\title{
Helplessness, self blame and faith may impact on self management in COPD: a qualitative study
}

\author{
*Nicolette Sheridana, Timothy Kenealy", Elizabeth Salmon', Harold Read, \\ Deborah Raphael ${ }^{a}$, Jacqueline Schmidt-Busby ${ }^{a}$
}

\author{
a School of Nursing, Faculty of Medical and Health Sciences, University of Auckland, Grafton, New Zealand \\ ${ }^{\mathrm{b}}$ Department of Medicine, General Practice \& Primary Health Care, South Auckland Clinical School, University of Auckland, New Zealand \\ ' Department of Respiratory Medicine, North Shore Hospital, Waitemata District Health Board, Auckland, New Zealand \\ ${ }^{\mathrm{d}}$ Department of Respiratory Medicine, Counties Manukau District Health Board, Auckland, New Zealand
}

Original submission 29th May 2010; re-submitted 5th October 2010; revised 15th December 2010; further revision 2nd February 2011; accepted 22nd February 2011; online 21st April 2011

\begin{abstract}
Aims: To explore how patients with COPD experience helplessness.

Methods: In-depth interviews with 29 patients with moderate to very severe COPD. Data were analysed using a general inductive approach.

Results: All patients focused on acute symptoms and expressed feelings of helplessness in the management of their condition; little attention was paid to longer-term strategies. For one group of patients, mostly European, self blame appeared to intensify feelings of helplessness. For a second group, mostly Pacific, a focus on faith in God, Church and family provided a more positive affect and existed alongside helplessness.

Conclusions: Clinicians seeking to support patients to include longer term strategies in their self management will need to coach patients to experiences of short-term success, and be aware of the ways that patients experience and interpret their helplessness. Clinicians need to address self blame, and recognise patients' priorities of faith and family.

(C) 2011 Primary Care Respiratory Society UK. All rights reserved.

N Sheridan et al. Prim Care Respir J 2011; 20(3): 307-314

http://dx.doi.org/10.4104/pcrj.2011.00035
\end{abstract}

Keywords COPD, helplessness, self blame, self management, faith

See linked editorial by Kaplan and Small on pg 233

The full version of this paper, with online Appendix,

is available at www.thepcrj.org

\section{Introduction}

Chronic obstructive pulmonary disease (COPD) is a life threatening lung disease that affects an estimated 210 million people worldwide and is expected to increase by more than $30 \%$ in the next ten years. ${ }^{1}$ In New Zealand COPD is the fourth leading cause of death. ${ }^{2}$ It is characterised by gradual but relentless deterioration, distressing recurrent exacerbations, and symptoms that become debilitating.

Although COPD is not curable, appropriate treatment built around self management is central to reducing severity or frequency of exacerbations, preventing hospitalisations and improving health-related quality of life.-5 Self management appears to be effective whether the COPD is mild, moderate or severe. ${ }^{3}$ However, many self management strategies are complex and require significant effort and commitment from patients. ${ }^{6}$ These include smoking cessation, breathing and coughing techniques, exercise programmes, regular inhaled medication and the self-initiation of corticosteroids or antibiotics at the onset of an exacerbation, deploying effective behavioural skills, ${ }^{8}$ and self management education. ${ }^{9}$

Psychological factors are presumed to play a role in patients' self management, and influence the degree to which individuals can improve personal skills and knowledge.

\footnotetext{
* Corresponding author: Dr Nicolette Sheridan, Senior Lecturer, School of Nursing, Faculty of Medical and Health Sciences, University of Auckland, Private Bag 92019 Auckland 1142, New Zealand. Tel: +64 99237811 Fax: +64 93677158 E-mail: n.sheridan@auckland.ac.nz
} 
Anxiety, panic, fear, frustration, depression, regret and social isolation are feelings that contribute to the emotional burden of COPD, ${ }^{10,11}$ with many accepting their condition with a sense of helplessness ${ }^{12}$ - a perception that whatever we do will make no difference to the future. ${ }^{13,14}$ An overwhelming sense of helplessness might undermine a patient's motivation to engage in complex therapies in COPD. Helplessness may also be reinforced by repeated experiences of failure to control symptoms, which are presumably deeply rooted in the experience of living with this condition.

We therefore sought to explore, in a specific New Zealand context, whether individuals with moderate to very severe COPD experience helplessness, how they interpret this, and the consequences for their self management including the services they access.

\section{Methods}

A qualitative methodology was chosen to gain a detailed understanding of patients' beliefs and experiences. ${ }^{15,16}$ Two COPD patient groups were identified for theoretical and pragmatic reasons. In the first eight patient interviews conducted in one locality (Table 1, Group 1), we noted an interesting theme - self blame - in the European participants which was not apparent in the one participant from the Cook Islands. We therefore extended our sample to a second locality to include a greater number of Pacific people (Table 1, Group 2), specifically to explore whether they too experienced self blame. This pragmatic sampling strategy allows for comparison between two ethnically different groups.

All participants had moderate, severe or very severe COPD and were identified from the emergency care database as having been admitted to a large urban teaching hospital in New Zealand at least twice within 12 months. Group 1 patients had been admitted between January and December 2008, and Group 2 patients admitted between January and December 2009 to a different hospital. The first group resided in a relatively affluent semi-rural region, whereas the second group resided in an impoverished urban region. Two of the authors (HR, ES) are clinicians in the respiratory medicine departments of the two hospitals. No participant was under the clinical care of either clinician.

Eligible people were contacted by a research nurse between four and eight weeks after discharge from hospital and invited to participate in the study. One week later a letter was sent providing a fuller explanation of the study. A second phone call confirmed participation, answered any questions and scheduled a date for interview. All who were invited to participate accepted. All participants chose to be interviewed in their homes; two people in hospital on the day of the interview were not interviewed. Participant information and consent forms were translated from English into both Samoan and Tongan languages. Written informed consent was gained on the day of the interview.

Three research nurses of European or Pacific Island descent conducted in-depth interviews ranging between 60 and 90 minutes in the patients' preferred language. Interviews were therefore conducted in either English, Samoan or Tongan languages using a common interview topic guide. Four main areas were explored: the experience of living with COPD; understanding and managing symptoms and therapies; self care; and receiving health care (see Appendix 1, Interview topic guide, available online at www.thepcrj.org). Although we had an area of interest, we did not set variables to be studied, thereby allowing for unanticipated knowledge: ${ }^{17}$ having the flexibility to discuss what is meaningful| ${ }^{17,18}$ and gaining rich detail ${ }^{19}$ are hallmarks of this methodology. Participants could invite a support person to attend the interview and were able to stop the interview if they became breathless or did not want to continue. All participants consented to their interview being recorded. Cassettes were labeled with a code to ensure anonymity after interview.

Interviews were transcribed and translated before being coded and entered into a software system (NVivo 8). Those that had been translated were reviewed by a person of the same language group. A general inductive approach was used to identify themes that emerged from the data. Transcripts were read several times and interpretation of the data was discussed within the wider research team. We confirmed accuracy by obtaining participants' hospital discharge letters to verify the number of admissions, length of stay, and the referrals made to consultant respiratory physicians in the study period. Ethical approval from the Northern X Regional Ethics Committee was obtained (Refs. NTX/08/06/048; NTX/09/03/EXP).

\section{Results}

Patients in Group 1 ranged between 65 and 89 years of age; five were female, seven were of European descent and one was of Cook Island Māori ethnicity. All had severe or very severe COPD by GOLD criteria, ${ }^{20}$ with a forced expiratory volume in one second $\left(\mathrm{FEV}_{1}\right)$ ranging from 18 to $38 \%$ predicted on postbronchodilator spirometry and with two to six admissions to hospital in the previous year for acute exacerbations of COPD. Five reported "recently" having stopped smoking cigarettes. Four claimed routine follow-up with a general practitioner (GP) and one with a respiratory physician. Only two were on long term oxygen therapy (LTOT), and three had never been assessed, including the patient with the lowest $\mathrm{FEV}_{1} \%$ predicted. Each had two or more significant co-morbidities such as congestive heart failure, ischaemic heart disease or type 2 diabetes.

Group 2 consisted of 21 participants ranging between 50 and 84 years of age; nine were female. Seventeen participants were Pacific peoples - Samoan, Tongan, Cook Island Māori and 
Helplessness, self blame and faith in COPD

Table 1. Demographic characteristics of patients

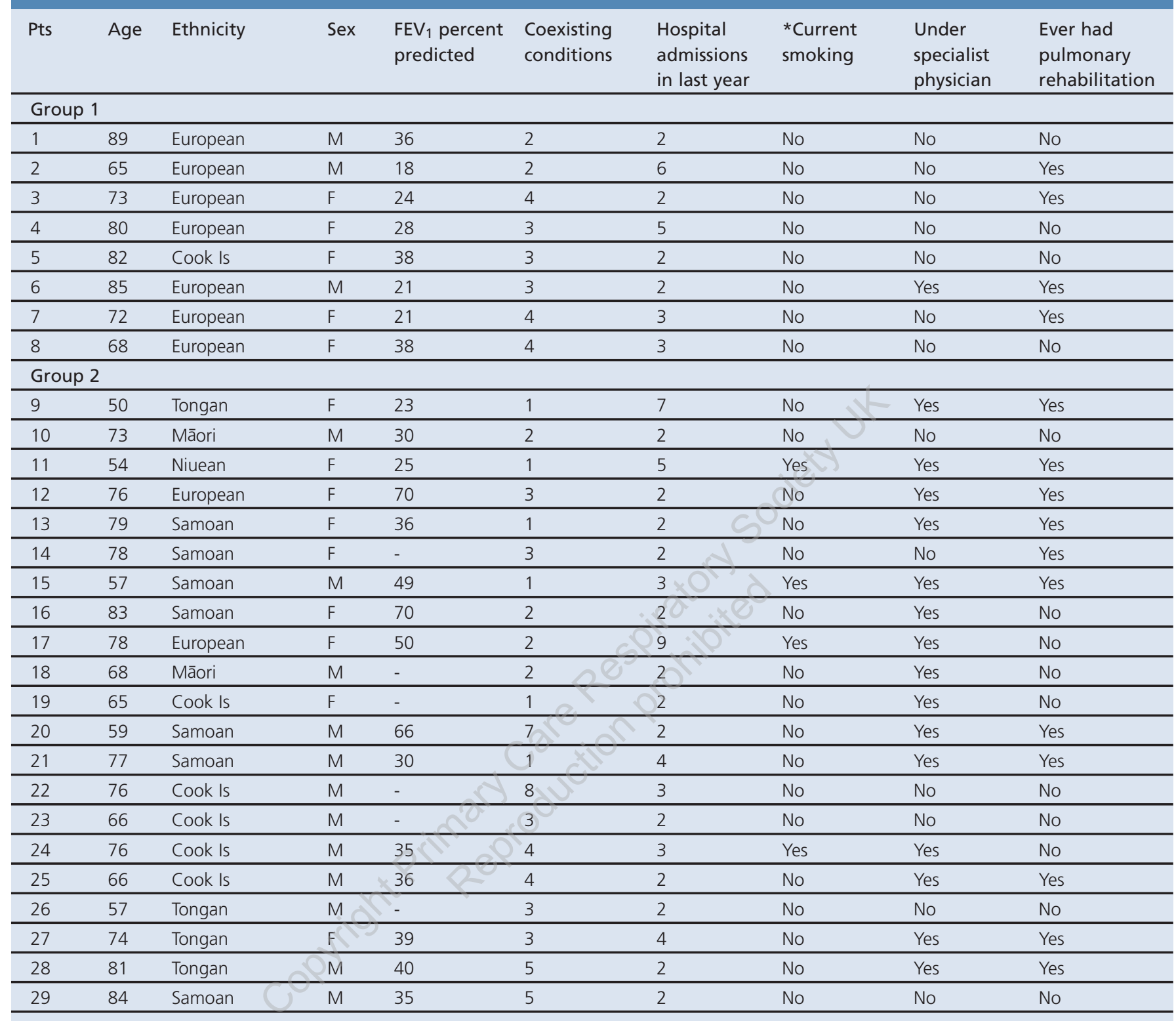

*All patients have a history of cigarette smoking.

Participants with forced expiratory volume in one second $\left(\mathrm{FEV}_{1}\right)$ \% predicted NOT recorded had hospital admissions for clinically severe lung disease (bronchiectasis or cor pulmonale) or an overriding co-morbidity (paraplegia or end stage renal failure).

Niuean; two were Māori and two of European descent. All had COPD by GOLD criteria ${ }^{20}$ with $\mathrm{FEV}_{1}$ ranging from 23 to $70 \%$ predicted on post-bronchodilator spirometry. The two youngest participants (aged 50 and 54 years) had the lowest $\mathrm{FEV}_{1}$ percent predicted at $23 \%$ and $25 \%$, respectively. In the previous year the number of admissions to hospital for acute exacerbations of COPD ranged from two to nine. Five participants were current smokers. In contrast to Group 1, most were under the care of a respiratory physician and half had received pulmonary rehabilitation. All had similar co-morbidities to those in the Group 1 with 11 having more than four conditions.
Two central themes were identified from Group 1. The first was helplessness, seen in passive resignation and poor selfmanagement of their condition, and the second was self blame (individuals blamed themselves for their illness) because they had smoked cigarettes.

We explored these themes with participants interviewed in Group 2 to compare with the experiences of those in Group 1. We did not identify self blame in any interview with a Pacific person, but a third theme emerged: all Pacific participants articulated strongly held beliefs in God, the Church and family and repeatedly reported these to be the most important things 
in their lives. However, this marked difference did not mitigate individuals' inability to self manage.

We concluded that all participants shared the same human experiences of living daily with debilitating symptoms and feelings of helplessness. Despite differences in the ways groups interpreted their illness and their lives, we argue that the common experience of helplessness undermined their ability to self manage in both the short and long term.

\section{Living with debilitating COPD symptoms}

The most common and most distressing physical symptoms were breathlessness and fatigue, identified by every participant:

I get very, very breathless when exerting myself... I'd be half dead and gasping away... coughing up phlegm - you just about turn yourself inside out (European man, 85 years)

I am weak, unhappy, short of breath and cough (Samoan man, 57 years)

Many described parallel psychological symptoms of anxiety, panic, fear, frustration, depression, and social isolation:

You can't breathe - it's a - it's a, you panic and it makes it worse (European man, 89 years)

If I walk from here to the road, I am always short of breath, have a headache and not feeling well. I am not working any more as instructed by my doctor due to shortness of breath... I don't sleep well. I wake every night 3-4 times per night. I am not as happy as I used to be. I don't go to see my friends anymore. (Samoan man, 59 years)

And this is what people have to become aware of, how draining it is when you can't breathe and you struggle for every breath, it drains you, it absolutely destroys you, when you do something you are so tired so exhausted afterwards across the diaphragm here gets so painfully sore because every breath is a strain, you've got no idea (European man, 65 years)

It does worry you being like this ... and you do get fed up with it, and it gets you down... at times I get quite weepy (European woman, 73 years)

Sometimes I get so scared, once I get frightened my heart starts to beat - it affects me. I can't breathe (Cook Island woman, 82 years)

\section{Helplessness}

Participants talked of having little control over distressing symptoms such as breathlessness, and indicated they believed little could be done by themselves or others. An overwhelming sense of helpless prevailed, faced with a future that was happening despite them. Helplessness appeared to act as a barrier to taking action that could prevent or reduce acute exacerbations. One Samoan man described "having to go with it" (59 years). Other participants spoke of deterioration:

Now I just have to put up with it, now that I've got it um never gets any better (European woman, 80 years)

You gotta plod along don't you (European woman, 73 years)

If it gets worse it just happens... just have to carry on and see what happens (European man, 89 years)

Furthermore, helplessness appeared to be reinforced by repeated bad experiences:

I use the walking frame and can rest up, but I get panic attacks now. My physio has taught me (breathing techniques) but I get annoyed when it doesn't help and I panic... I call the ambulance (Nuiean woman, 54 years)

\section{Poor understanding of COPD}

COPD was confused with asthma, and acute exacerbations of COPD were confused with temporary exacerbations of asthma. This misunderstanding led to a perception of COPD being both reversible and less severe:

I get a bit crook with my asthma all the time (European woman, 80 years)

I am not working anymore...due to a shortness of breath from my asthma (Samoan man, 59 years)

Despite all patients suffering recurrent exacerbations, and several participants specifically mentioning a fear of dying during an exacerbation, the relentlessly progressive nature of the underlying condition was poorly understood by the majority:

I do see myself as possibly getting better (Niuean woman, 54 years)

A 68 year-old woman, severely debilitated by her condition, held the mistaken belief that having given up smoking her condition would not deteriorate:

Now that I've stopped smoking... I will slowly, well I won't get any worse put it that way. I might not get a lot better but I won't get any worse (European woman, 68 years)

\section{Poor self management}

Most had no recollection of being taught strategies to help them manage their symptoms and had devised their own practical ways of managing. In particular, they lacked understanding around the importance of recognising early symptoms of an exacerbation to help prevent hospitalisation and slow the decline of lung function. Few participants had 
action plans to direct early self management of an acute exacerbation. Most had been admitted to hospital with an exacerbation of COPD in the previous six months. A European woman (72 years) recalled being told by her GP the only instruction she was given specific to managing an exacerbation "If you get any worse you know what to do ring up for the ambulance". In the previous 12 months she called the ambulance three times.

There was poor understanding around appropriate medication use:

I've got spacers but I don't use them because I don't feel any benefit from them (European woman, 68 years)

Because she found no benefit from salbutamol, this woman also stopped using her spacer device for her eformoterol and fluticasone. Inappropriate and excessive use of nebulised medication was common. For example, the inability to interpret repeated nebuliser use as a critical sign of the need for alternative treatment, or of deterioration, was apparent in the following comment made by a man who had been hospitalised six times within 12 months:

Probably six or eight times a day I use it, I use it 'bout half a dozen times during the night (European man, 65 years)

\section{Poor information and education}

Confusion and frustration in the face of conflicting information was not uncommon:

You never know what you've got with these doctors... you get told this and you get told that (European woman, 80 years)

Lately every time I come into hospital (I find out) things that I thought I maybe should've known two years ago (European man, 65 years)

The main contribution from GPs was seen as prescribing, but frequently in isolation from information needs. One Samoan man (57 years) commented that his doctor helped him, "He gives me medications and inhalers". Another participant received a prescription but without information about how to take the medication:

I didn't ever get shown how to use the spacer until the chemist showed me (Tongan woman, 50 years)

In general, participants liked their GP because they had an established relationship. A Cook Island woman explained that she felt comfortable with her GP because he was from the same ethnic background. Nevertheless, this woman was not under a respiratory physician nor has she ever had pulmonary rehabilitation, despite two recent hospitalisations. Another commented on general practice, "I like them all there, they are easy to get on with" (European woman, 68 years), even though she had been hospitalised three times during the past year and was referred to a respiratory physician only on the last admission because she had been discharged on home oxygen, and she has never received pulmonary rehabilitation. Half of the participants had not received pulmonary rehabilitation or been referred to a respiratory physician. Overall, actual care and support was below that recommended by COPD guidelines.

\section{Self blame}

The majority of participants attributed the cause of their COPD to having smoked cigarettes. Seven European participants blamed themselves for this and expressed regret:

I smoked for 52 years... but I don't bemoan the fact, I appreciate it was my own doing and er l've just got to ride the thing through (European man, 85 years)

Well it's just something l've got to put up with (European woman, 72 years)

I knocked it off 5 years ago... I should have done it a long time ago (European woman, 80 years)

Being told by a doctor "it's your own fault" (European woman, 72 years) only reinforced feelings of guilt and shame; this was not uncommon. Self blame was not apparent in the Pacific participants, who had smoked for years, and appeared to accept without guilt that smoking had caused their condition; five were current smokers.

\section{Faith (God, Church and family)}

All Pacific participants looked to God, the Church and family and this appeared to help them live with their illness. A strong valuing of life, and life beyond this present existence, was apparent:

I look after my health very well and I pray to God to give life and strength (Samoan woman, 79 years)

It is highly important to know spiritual health as we believe that we only live here temporarily, one day we will go (Tongan man, 57 years)

I know that it is important for us to pray and keep trying and not just give up, and we are told to wait till death comes. Keep calling our God for his help and wait for his call (Tongan woman, 74 years)

The majority of the Pacific participants reported "Church and family" as the most important things in their lives. Not being able to attend Church and "church activities" disrupted not only spiritual life, but family life and wider social relationships. One Cook Island woman talked of the importance of the fellowship group for women in her Church. Another said:

Very important, spiritual life, if we weren't at Church, I believe we won't have a happy family and be blessed 
with such obedient children.... no one drinks alcohol, no one smokes cigarettes... they will have good futures (Tongan man, 57 years)

Going to Church was commonly the last remaining activity Pacific participants engaged in outside of the home. Deep sadness at being unable to go to Church was expressed even though most were visited by members of the congregation, ministers, friends and family. Attendance at Church depended almost entirely upon "being [sufficiently] well" and going less often reflected deteriorating illness:

I'm not able to go to any activities at Church when I'm unwell (Tongan man, 81 years)

I've already resigned from my positions in Church (Samoan man, 59 years)

All Pacific and Māori participants lived with a partner and often also with other family members; no one lived alone. In contrast three European participants lived alone, and most reported being lonely. It appeared that being well enough to spend time with family and helping the family, enhanced quality of life:

It's important to be with my family and children every day, my seven children, 21 grandchildren and 14 great-grandchildren (Samoan man, 84 years)

The best thing is being alive and spending time with my children (Tongan woman, 74 years)

\section{Discussion}

Our patients confirm a pervasive sense of helplessness and poor self management focused only on managing current distressing symptoms, as has been reported previously. What is new relates to the identification of two distinct approaches that co-exist with, and may support, these attitudes and behaviours. The first is a sense of self blame and negative affect in a small group, mostly European, with limited family contact. The second is a more positive affect in a group (mostly Pacific) for whom God, Church and family are consistently acknowledged as being central to their lives.

The common and distressing psychological and physical symptoms reported by all participants are consistent with the literature. ${ }^{10,12,21,22}$ Dying of breathlessness or suffocation was a deep fear expressed by participants, and has also been reported previously. ${ }^{23}$ Short term or 'rescue' medication was therefore the most commonly used treatment, anywhere from once a day to eight or more times in a few hours. Participants showed an emotional attachment to short term medications and reported immediate relief as a top treatment concern.

Most participants used short term medications in place of long term treatments without distinction in the hope of managing symptoms. Most had little knowledge of maintenance therapies. Several could not name their condition as COPD. All described frequent, worsening exacerbations requiring hospitalisation. Although all recognised that their condition had deteriorated, some thought it would not get any worse, while others spoke about their fears of dying because they could not breathe.

Patients in Group 1 blamed themselves for having caused their disease because they smoked. This group also reported limited social support from their families and social networks, factors negatively associated with managing illness. ${ }^{24}$ Previous research has shown that those with COPD believe that others think they have "brought on their condition themselves"11 and recent evidence supports stigmatisation of COPD within wider society as a self-inflicted disease. ${ }^{11,24}$ In this study, patients said that doctors and nurses blamed them for their condition, a finding consistent with a UK survey of 184 hospital doctors which found respondents believed that patients with COPD were "at fault" for their condition. ${ }^{25}$ Self blame was consistently associated with low expectations of care almost if as patients thought that they "did not deserve better", and this was reinforced when clinicians echoed this blame.

Patients in Group 2 did not appear to blame themselves or anyone else for their condition. This may be because Pacific culture does not view smoking in a negative context as it is perceived within Western culture. ${ }^{24}$ In addition, a strong emphasis is placed on social relationships and at family and community events smoking is a common, shared social activity. ${ }^{26}$ Pacific people view their own health as less important than Church, family and work commitments. ${ }^{26}$ We found that participants spontaneously and repeatedly referred to family, Church and God as being central to their lives and providing a meaningful focus beyond that of the illness. Family presence acted as a safety net, ${ }^{27}$ for example, with participants describing being helped to reach their bed or a chair when breathless and "unable to move". Like the patients in Group 1, Pacific patients were similarly physically affected and their self-management also centered on present symptoms rather than on longer-term strategies.

Helplessness may undermine the sense of control that is the key to improving COPD patients' health-related quality of life. ${ }^{5}$ This has been noted in other cultures. ${ }^{28}$ Clinician attitude and action can be crucial in influencing patient attitudes toward a disease and its management, ${ }_{1}^{29}$ and some research even suggests that physician attitudes toward chronic condition management might be more important than their factual knowledge of the disease..$^{30} \mathrm{It}$ is concerning that self blame in the Group 1 patients, reinforced by clinicians and combined with a lack of support from their social networks, might further decrease their willingness to engage in self management. Our Group 2 patients - who appeared more positive and had faith in God and their families - were still uniformly resigned to living with 


\section{Summary}

There were no specific difficulties encountered during this study. Further research should explore helplessness, self blame and faith in other patient populations, using similar in-depth interviews. If our findings are confirmed then it would seem important to develop strategies to teach clinicians to recognise and address self blame in patients and their own blaming of patients themselves. Clinicians can assist patients by accepting their choices, desisting from blaming statements, supporting those who want to stop smoking, structuring care, and coaching people through repeated exacerbations until they have repeated experiences of success in managing their condition.

breathlessness and related symptoms and attempting to gain short term control. Again, there was little or no attention given to longer-term strategies.

We work from the premise that 'information is care'; self management education in COPD has been associated with a reduction in hospital admissions. ${ }^{31}$ Facilitating access to effective education and wider relevant information is a core function of any health professional. It seems that these COPD patients did not always receive the right information about their illness or its management; or alternatively that the knowledge transfer was ineffective. To counter recurrent negative patient experiences and create new expectations of care requires that we coach patients in managing exacerbations of COPD - which is a goal of pulmonary rehabilitation..$^{32}$ It is essential to place an emphasis on optimising function between exacerbations and managing expectations about the condition over a longer term. This requires clinicians to provide structured care that delivers guideline-standard interventions.

This study was designed to deepen our understanding of helplessness and the effect this has on patient self management. This should be an integral part of disease management for those clinicians who want to support patients to manage their condition better (both in the short and longer term) and to lessen their associated emotional burden. Whilst helplessness in the management of COPD was a common patient experience in our study, co-existing attitudes differed in ways that may be important to clinicians. For Group 1 patients, clinicians need to stop blaming patients, and they may need to address self blame and engage allied services to enhance patient social support. For Group 2 patients, they may be able to link long term strategies with enhancing patients' prospects of enjoying God, Church and family.

In our two research localities, care appeared fragmented for people with moderate to very severe COPD who lack a coordinated long term approach. ${ }^{33}$ These findings are supported by the limited literature on experiences of health care provision for this group of people. Further research should explore helplessness, self blame and faith in other patient populations, using similar in-depth interviews. If our findings are confirmed it would be appropriate to develop and validate a question guide for routine use with patients, to help clinicians engage better with patients within their own world-view and building on personal and cultural strengths.

\section{Conflicts of interest}

None

\section{Funding}

This work was partially funded by a grant from the New Zealand Tertiary Education Commission, Strategy To Advance Research (STAR) project.

\section{References}

1. World Health Organization. Fact Sheet 315: Chronic obstructive pulmonary disease (COPD). 2009 [cited 2010 January 12]. Available from: http://www.who.int/mediacentre/factsheets/fs315/en/index.html.

2. Asthma Foundation. COPD in New Zealand. 2010 [cited 201012 January]. Available from: https://www.asthmafoundation.org.nz/copd_in_new_zealand.php.

3. Bourbeau J, Julien M, Maltais F, et al. Reduction of hospital utilization in patients with chronic obstructive pulmonary disease: a disease-specific selfmanagement intervention. Arch Intern Med 2003;163:585-91. http://dx.doi.org/10.1001/archinte.163.5.585

4. Rea H, McAuley S, Stewart A, Lamont C, Roseman P, Didsbury P. A chronic disease management programme can reduce days in hospital for patients with chronic obstructive pulmonary disease. Internal Medicine Journal 2004,34(11):608-14

5. Bourbeau J, Nault D, Dang-Tan T. Self-management and behaviour modification in COPD. Patient Educ Couns 2004;52(3):271-7. http://dx.doi.org/10.1016/S0738-3991(03)00102-2.

6. Ries AL, Kaplan RM, Myers R, Prewitt LM. Maintenance after pulmonary rehabilitation in chronic lung disease: a randomized trial. Am J Respir Crit Care Med 2003;167(6):880-8

7. Pauwels R, Buist A, Calverley P, Jenkins C, Hurd S. Global Strategy for the Diagnosis, Management, and Prevention of Chronic Obstructive Pulmonary Disease. NHLBIMHO Global Initiative for Chronic Obstructive Lung Disease (GOLD) Workshop Summary. Am J Resp Crit Care Med 2001;163:1256-76.

8. Scharloo M, Kaptein A, Schlösser M, et al. Illness perceptions and quality of life in patients with chronic obstructive pulmonary disease. J Asthma 2007;44:57581. http://dx.doi.org/10.1080/02770900701537438.

9. Bodenheimer T, Lorig K, Holman H, Grumbach K. Patient self-management of chronic disease in primary care. JAMA 2002;288(19):2469. http://dx.doi.org/10.1001/jama.288.19.2469.

10. Elkington $H$, White $P$, Addington-Hall J, Higgs $R$, Pettinari $C$. The last year of life of COPD: a qualitative study of symptoms and services. Resp Med 2004;98(5):439-45. http://dx.doi.org/10.1016/j.rmed.2003.11.006.

11. Emphysema Foundation for Our Rights to Survive (EFFORTS). Emotional burden of COPD - chronic bronchitis and empysema - may make patients reluctant to seek treatment, survey shows. 2006 [cited 20098 November]. Available from: http://www.emphysema.net/pressrel.htm.

12. Omachi TA, Katz PP, Yelin EH, et al. The COPD helplessness index: a new tool to measure factors affecting patient self-management. Chest 2010;137(4):823-30. http://dx.doi.org/10.1378/chest.09-0764.

13. Bandura A. Social foundations of thought and action: a social cognitive theory. Englewood Cliffs, New Jersey: Prentice-Hall; 1986.

14. Stein M, Wallston K, Nicassio P, Castner N. Correlates of a clinical classification schema for the arthritis helplessness subscale. Arthritis and Rheumatism 1988;31(7):876-81. http://dx.doi.org/10.1002/art.1780310708.

15. Creswell JW. Research design: Qualitative, quantitative, and mixed methods approaches. Thousand Oaks CA: Sage Publications; 2003.

16. Farquhar SA, Parker EA, Schulz AJ, Israel BA. Application of qualitative methods 
N Sheridan et al.

in program planning for health promotion interventions. Health Promotion Practice 2006;7(2):234-42.

17. Patton MQ. Qualitative research and evaluation methods. Thousand Oaks, CA: Sage; 2002.

18. Mcllfatrick S. Assessing palliative care needs: views of patients, informal carers and healthcare professionals. J Adv Nursing 2007;57(1):77-86.

19. Britten N. Qualitative Interviews. In: Pope C, Mays N, editors. Qualitative research in health care. Oxford: Blackwell Publishing; 2006.

20. Roisin R, Rabe K, Anzueto A, et al. Global Initiative for Chronic Obstructive Lung Disease. Global strategy for the diagnosis, management and prevention of chronic obstructive pulmonary disease; 2008.

21. Barnett M. Chronic obstructive pulmonary disease: a phenomenological study of patients' experiences. J Clinl Nurs 2005;14(7):805-12. http://dx.doi.org/10.1111/j.365-2702.005.01125.x.

22. Edmonds $P$, Karlsen $S$, Khan S, Addington-Hall J. A comparison of the palliative care needs of patients dying from chronic respiratory diseases and lung cancer. Palliat Med 2001;15(4):287-95. http://dx.doi.org/10.1191/026921601678320278.

23. Gardiner C, Gott M, Small N, et al. Living with advanced chronic obstructive pulmonary disease: patients concerns regarding death and dying. Palliat Med 2009;23(8):691-7.

24. Halding AG, Heggdal K, Wahl A. Experiences of self-blame and stigmatisation for self-infliction among individuals living with COPD. Scand J Caring Sci 2011; 25(1):100-07. http://dx.doi.org/10.1111/j.1471-6712.2010.00796.x.

25. Winstanley L, Daunt M, Macfarlane J. Doctors' attitude towards current smokers with chronic obstructive pulmonary disease and its impact on delivering smoking cessation advice. J Smok Cessat 2008;3(2):133-5

26. The Quit Group. Health, smoking and cessation: research findings from Pacific Health Service Providers and Community Leader Fono Groups. Wellington: The Quit Group; 2003.

27. Chen K, Chen M, Lee S, Cho H, Weng L. Self-management behaviours for patients with chronic obstructive pulmonary disease: a qualitative study. J Adv Nurs 2008;64(6):595-604.

28. Yu DSF, Lee DTF, Wu J. The revolving door syndrome: the Chinese COPD patients' perspectives. J Clin Nurs 2007;16(9):1758-60.

29. Dietrich U. Factors influencing the attitudes held by women with type ॥ diabetes: a qualitative study. Patient Educ Couns 1996;29:13-23. http://dx.doi.org/10.1016/0738-3991(96)00930-5.

30. Weinberger M, Cohen S, Mazzuca S. The role of physicians' knowledge and attitudes in effective diabetes management. Soc Sci Med 1984;19(9):965-9. http://dx.doi.org/10.1016/0277-9536(84)90326-5.

31. Effing $T$, Monninkhof EE, Zielhuis GG, et al. Self-management education for patients with chronic obstructive pulmonary disease. Cochrane Database of Systematic Reviews. 2007;(4)

32. Williams V, Bruton A, Ellis-Hill C, McPherson K. The effect of pulmonary rehabilitation on perceptions of breathlessness and activity in COPD patients: a qualitative study. Prim Care Respir J 2010;19(1):45-51. http://dx.doi.org/10.4104/pcrj.2009.00044

33. Sheridan $N$, Kenealy $T$, Parsons $M$, Rea $H$. Health reality show: regular celebrities, high stakes, new game: a model for managing complex primary health care. N Z Med J 2009:122(1301):31-42.

\section{Available online at http://www.thepcrj.org}


Helplessness, self blame and faith in COPD

Appendix 1: Interview topic guide

\section{Experience of living with COPD}

- Perception of health and wellness

- Impact of illness on daily life

- Expectations about the future

2. Understanding and managing symptoms and therapies

- Knowledge of the condition

- Symptom interpretation

- Symptom management - acute and longer term
3. Self care

- Ways of managing symptoms

- Longer term strategies for managing COPD

- Interactions / relationships with family, others in the community

\section{Health care}

- Services accessed and treatments received

- Interactions / relationships with health professionals, other health workers

- Experience of encounters when seeking care 